\title{
Equality in the distribution of health material and human resources in Guangxi: evidence from Southern China
}

\author{
Jian Sun ${ }^{*}$
}

\begin{abstract}
Objective: The aim of this study was to assess the equality in the distribution of health material and human resources in Guangxi, and put forward proposal to improve the equality status of the health material and human resources.

Results: We used concentration index to evaluate the degree of income-related equality of health material and human resources. The concentration index values of the five resources ranged from -0.0847 to 0.1416 from 2011 to 2015. Health institution was concentrated among the poorer populations, while other four resources were concentrated among the richer populations. Overall, the equality status of health institutions, health care beds, health technical personnel, and certified nurses got better from 2011 to 2015. However, the equality status of practicing physicians has got worse since 2014.
\end{abstract}

Keywords: Equality, Health material and human resources, Concentration index, Guangxi

\section{Introduction}

Allocating the health material and human resources equitably is one of the foundations of health services development [1]. However, most of Guangxi's health material and human resources are concentrated among the developed areas, while the remote and developing areas have fewer resources [2]. Inequality in the distribution of health material and human resources seriously hinders the overall improvement of health, which is a concern in the health reform and Healthy Guangxi 2030 strategy.

Evaluating equality in the distribution of health material and human resources in Guangxi is particularly significant for several reasons. On the one hand, Guangxi is an underdeveloped area in China [3]. There exist regional gaps in socio-economic development and health material and human resources allocation within Guangxi [4]. Thus, the equality status in the distribution of health material and human resources is not good [4]. On the

\section{*Correspondence: 290981511@qq.com}

School of Humanities and Social Science, Guangxi Medical University, 22 Shuang Yong Road, Qing Xiu District, Guangxi Zhuang Autonomous Region, Nanning 530021, China other hand, health material and human resources are important economic resources, playing a vital role in improving people's overall health [5]. The unbalance distribution of health material and human resources hinders the availability of health services, which might result in social conflicts in Guangxi [6].

Studies have showed that the equality status of health material and human resources in Guangxi was poor and needed to be improved. A study in Guangxi found that the health human resources were mainly concentrated among the richer populations, and the equality status remained to be improved [2]. Guo [7] reported that the equality status of health material and human resources allocation in the 14 cities of Guangxi is poor, thus the government should increase the number of health resources and constantly improve the equality status of health material and human resources. Sun [8] concluded that the equality status of health care beds and health technical personnel in Guangxi was much better than that of health institutions and practicing physicians. The aim of this study was to assess the equality in the distribution of health material and human resources in Guangxi, and put forward proposal to improve the equality status 
of the health material and human resources. The results of this study could provide references for the government to rationalize the allocation of health material and human resources in Guangxi.

\section{Main text \\ Methods \\ Data sources and statistical analysis}

Demographic, economic, geographic area, and health material and human resources data was obtained from the Guangxi Statistical Yearbook 2012-2016 [9-13]. Furthermore, Microsoft Excel 2013 was employed to enter data, draw figures and calculate concentration index.

\section{Concentration index}

Concentration index was adopted to evaluate the degree of income-related equality of health material and human resources. The concentration index is defined as twice the area between the concentration curve and the line of equality (the diagonal line) [14]. The concentration index was calculated as:

$$
\begin{aligned}
& \mathrm{S}=\frac{1}{2} \sum_{i=0}^{n-1}(Y i+Y i+1)(X i+1-X i) \\
& \mathrm{CI}=2 \times(0.5-\mathrm{S}),
\end{aligned}
$$

where $Y_{0}$ equals 0 and $X_{0}$ equals $0 ; Y_{i}$ is the cumulative proportion of health material and human resources, $X_{i}$ is the cumulative proportion of population, and $\mathrm{i}$ is the fractional rank according to per capita gross domestic product beginning with the lowest; CI represents the concentration index [15].

The concentration index ranges between -1 (pro-poor) and +1 (pro-rich); the greater the absolute value of concentration index, the greater the degree of inequalities; a value of zero indicates absolute equality; a negative value indicates a concentration of the resource on the poorer populations; a positive value indicates a concentration of the resource on the richer populations [16-26].

\section{Main indicators}

Based on a review of related literature [2], we selected the health institutions, health care beds, health technical personnel, practicing physicians, and certified nurses as evaluation indicators. The definitions of the five indicators are shown as following.

1. Health institutions refer to the institutions that have got the legal registration certificates from the health department, such as hospitals, primary health institutions, public health institutions and other health institutions [1].
2. Health care beds refer to the number of beds in health institutions [1].

3. Health technical personnel refers to practicing physicians, certified nurses, pharmacists, radiologists, and other health professionals that work in health institutions [1].

4. Practicing physicians refer to the physicians that have got the legal practicing physicians certificates [1].

5. Certified nurses refer to nurses who have obtained the legal practicing nurses certificates [1].

\section{Guangxi Zhuang Autonomous Region}

Guangxi Zhuang Autonomous Region is an ethnic minority region in southern China and includes 14 prefecture-level cities. Guangxi has 11 ethnic minority groups, including the Zhuang, Yao, and Miao et al., which accounts for $38 \%$ of its population [27]. Guangxi is a less developed province in China, and the per capita gross domestic product of Guangxi was about 36,374 Yuan (approximately \$5269) [3].

\section{Results \\ Basic information of health material and human resources allocation in Guangxi from 2011 to 2015}

Table 1 showed the basic information of health material and human resources allocation in Guangxi from 2011 to 2015 . The number of the five health material and human resources had been increasing over time. Totally, the number of health institutions, health care beds, health technical personnel, practicing physicians, and certified nurses per 10,000 persons was all increased from 2011 to 2015 (Fig. 1), and they rose $26.45,36.01,33.02,37.50$, and $44.85 \%$, respectively. Meanwhile, the physician-nurse ratio was about 1:1.05-1.14.

\section{Regional distribution of health material and human resources in Guangxi in 2015}

In order to make a deeper understanding of health material and human resources distribution in Guangxi, we calculated the number of the resources per 10,000 persons and per square kilometer in the year of 2015.

Table 2 and Additional file 1: Figure S1 showed the regional distribution of health material and human resources per 10, 000 persons in 2015. The number of health institutions, health care beds, health technical personnel, practicing physicians, and certified nurses per 10,000 persons was $6.12,44.57,57.12,21.45$, and 23.61 , respectively. The number of health institutions per 10,000 persons in Guilin was 32 times more than that in Qinzhou. Compared with the number of health institutions, the degrees of disparity in other four resources were not as great. 


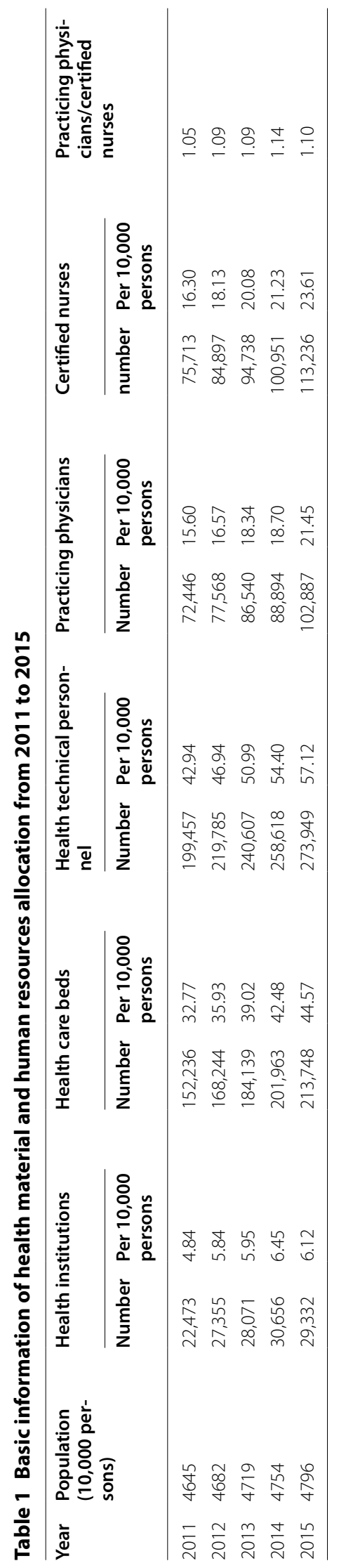




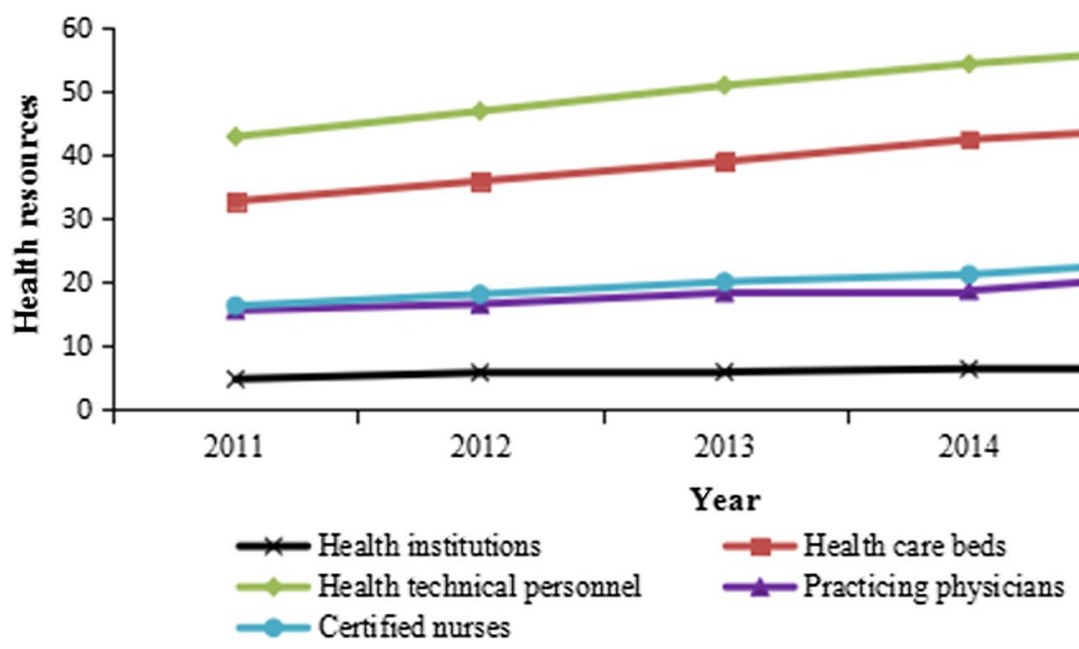

Fig. 1 Health material and human resources per 10,000 persons from 2011 to 2015

Table 2 Regional distribution of health material and human resources per 10, 000 persons in 2015

\begin{tabular}{llcllll}
\hline City & $\begin{array}{l}\text { Population } \\
(\mathbf{1 0 , 0 0 0} \text { persons) }\end{array}$ & Health institutions & Health care beds & $\begin{array}{l}\text { Health technical } \\
\text { personnel }\end{array}$ & $\begin{array}{l}\text { Practicing } \\
\text { physicians }\end{array}$ & Certified nurses \\
\hline Nanning & 698.61 & 3.95 & 58.77 & 82.27 & 28.87 & 35.73 \\
Liuzhou & 392.27 & 5.81 & 55.55 & 74.03 & 24.30 & 32.32 \\
Guilin & 496.16 & 10.70 & 39.56 & 60.42 & 39.61 & 25.01 \\
Wuzhou & 299.94 & 5.66 & 37.82 & 55.58 & 18.59 & 23.36 \\
Beihai & 162.57 & 6.47 & 49.30 & 55.78 & 20.16 & 22.98 \\
Fangchenggang & 91.84 & 6.79 & 43.06 & 57.51 & 19.96 & 22.54 \\
Qinzhou & 320.93 & 0.33 & 42.02 & 50.06 & 15.51 & 19.87 \\
Guigang & 429.37 & 9.98 & 33.50 & 42.93 & 13.72 & 15.96 \\
Yulin & 570.72 & 6.12 & 39.26 & 42.72 & 14.59 & 16.19 \\
Baise & 359.67 & 7.30 & 46.01 & 54.32 & 15.17 & 22.12 \\
Hezhou & 202.59 & 5.73 & 36.55 & 49.27 & 16.39 & 20.08 \\
Hechi & 347.68 & 6.58 & 44.78 & 52.34 & 15.72 & 21.49 \\
Laibin & 218.20 & 0.98 & 45.45 & 43.30 & 27.34 & 18.29 \\
Chongzuo & 205.45 & 7.01 & 40.11 & 50.58 & 21.45 & 21.00 \\
Total/average & 4796.00 & 6.12 & 44.57 & 57.12 & & 23.61 \\
\hline
\end{tabular}

Additional file 2: Table S1 and Additional file 3: Figure $\mathrm{S} 2$ presented the regional distribution of health material and human resources per square kilometer in 2015. The number of health institutions, health care beds, health technical personnel, practicing physicians, and certified nurses per square kilometer was 0.12 , $0.90,1.16,0.43$, and 0.48 , respectively. The number of health institutions per square kilometer in Guigang was 40 times more than that in Qinzhou. Among the five resources, the number of health technical personnel per square kilometer in the 14 cities showed the smallest gap.

\section{Analysis of concentration index}

The concentration index values of health material and human resources by population from 2011 to 2015 were shown in Additional file 4: Table S2. The concentration index values of the five resources ranged from -0.0847 to 0.1416 at the same time. The concentration index values of health institutions were negative, indicating this resource was concentrated among the poorer populations. In contrast, the concentration index values of other four resources were positive, indicating these resources were concentrated among the richer populations. The absolute values of concentration index of health technical 
personnel, practicing physicians, and certified nurses were significantly higher than those of health institutions and health care beds, which suggests that the equality status of material resources was better than that of human resources.

Additional file 5: Figure S3 presented the concentration index values of health material and human resources by population from 2011 to 2015 . In the meanwhile, the concentration index values of health institutions showed an overall upward trend, while the concentration index values of health care beds, health technical personnel, and certified nurses showed an overall downward trend, indicating the absolute values of concentration index of the four resources showed an overall downward trend. That is to say, the equality status of the four resources got better. Conversely, the absolute values of concentration index of practicing physicians showed an overall upward trend, indicating the equality status of the resource got worse.

\section{Discussion}

As mentioned above, totally, the equality status of health institutions, health care beds, health technical personnel, and certified nurses got better. This situation was consistent with other studies $[8,28]$. One reason leading to this trend could be the health reform in 2009. The central government of China has invested 127 million dollars to develop health material and human resources in health institutions to narrow the gaps in health services among people in different regions since 2009, which greatly improved the equality status of health material and human resources in different regions [29]. However, the equality status of practicing physicians has got worse since 2014. In addition, the concentration index values of practicing physicians were the highest among the five resources in the year of 2015, which indicates that the equality status was the worst. The most potential explanation for this result was the gaps of economics in different regions of Guangxi. Economically developed areas, such as Nanning, Guilin, and Liuzhou, can provide higher salary and better career development opportunities than the remote and underdeveloped areas [8]. Thus, practicing physicians prefer to work in developed areas, whilst the remote and underdeveloped areas, such as Yulin, Guigang, and Laibin, fail to attract adequate practicing physicians [2]. Consequently, the government should pay attention to the equality status of practicing physicians, and formulate preferential policies to encourage practicing physicians to work in remote and underdeveloped areas of Guangxi, and formulate policies to set up the rational flow mechanism of practicing physicians to improve the equality status of practicing physicians
[30]. In addition, the health institutions are supposed to introduce adequate practicing physicians in remote and economically underdeveloped areas by giving extra subsidies and other preferential policies to ameliorate the inequality status of practicing physicians [31]. Moreover, the medical universities in Guangxi need to enroll more clinical medical students and encourage them to work in remote and underdeveloped areas of Guangxi by giving some prizes [32].

In conclusion, this study provides important suggestive evidence for the equality in the distribution of health material and human resources in Guangxi by elucidating the changing trends of concentration index from 2011 to 2015. This study proves that concentration index was suitable to evaluate the equality of health material and human resources in Guangxi, and it is first time to find that health institutions in Guangxi were concentrated among the poorer populations.

\section{Limitations}

There are several limitations in this study. On the one hand, as the Guangxi Statistical Yearbook does not include the health investment of each city, we do not have the relevant data to assess the equality status of health investment. On the other hand, gender equality is a significant issue in health material and human resources allocation, but due to the limitation of the data, we are not able to evaluate the gender equality status of the health material and human resources.

\section{Additional files}

Additional file 1: Figure S1. Regional distribution of health material and human resources per 10,000 persons in 2015.

Additional file 2: Table S1. Regional distribution of health material and human resources per square kilometer in 2015.

Additional file 3: Figure S2. Regional distribution of health material and human resources per square kilometer in 2015.

Additional file 4: Table S2. Concentration index values of health material and human resources by population from 2011 to 2015.

Additional file 5: Figure S3. Concentration index values of health material and human resources by population from 2011 to 2015.

\section{Acknowledgements}

Not applicable.

Competing interests

The author declares that he has no competing interests.

\section{Availability of data and materials}

Data on which this study are based are available in Guangxi Statistical Yearbook 2012-2016 (http://www.gxtj.gov.cn/tjjj/tjnj/).

Consent for publication

Not applicable. 


\section{Ethical approval and consent to participate}

The study protocol was reviewed and approved by the Ethics Committee of Guangxi Medical University. All research was performed in accordance with the Declaration of Helsinki. Written informed consent was obtained from each volunteering participant based on inclusion criteria. Participants were informed that they could withdraw from the study at any point in time without any consequences and were also ensured of anonymity and confidentiality within the study.

\section{Funding}

The Program of Guangxi Zhuang Autonomous Region Association for Science and Technology for Young Teachers and Graduate Students in 2016 (Item Number: gui ke xie (2016] Z-46), The Program of Humanities and Social Science Research Center of Guangxi Medical University for Graduate Students in 2016 (Item Number: 2016RWY06), and Innovation Project of Guangxi Graduate Education in 2017 (Item Number:YCSW2017114).

\section{Publisher's Note}

Springer Nature remains neutral with regard to jurisdictional claims in published maps and institutional affiliations.

Received: 27 May 2017 Accepted: 23 August 2017

Published online: 29 August 2017

\section{References}

1. Liu W, Liu Y, Twum P, et al. National equity of health resource allocation in China: data from 2009 to 2013. Int J Equity Health. 2016;15:68.

2. Liang $S$, Wang Y, Feng $Q$, et al. Study on allocation and equality of health human resources in Guangxi. Guangxi Med J. 2016;38(4):521-4.

3. Ma Z, Huang H, Chen Q, et al. Mental health services in rural China: a qualitative study of primary health care providers. Biomed Res Int. 2015;2015:151053.

4. Sun J, Gu H, Wen Q, et al. Assessing equity in the distribution of hightechnology medical equipment in Guangxi: evidence from an ethnic minority region in Southern China. Int J Equity Health. 2017;16:81.

5. Li Y, Wang W, Zhang $X$, et al. Analysis on health resource allocation in Xinjiang Uygur Autonomous Region based on rank sum ratio method. Chinese J Health Stat. 2013;30(5):737-9.

6. Jin J, Wang J, Ma X, et al. Equality of medical health resource allocation in China based on the Gini coefficient method. Iran J Public Health. 2015;44(4):445-57.

7. Guo Z, Shi W. The study of equity of the health resource allocation in 14 cities in Guangxi Zhuang Autonomous Region. Chin Health Resour. 2012;15(3):212-5

8. Sun J, Wen Q. Theil index-based analysis of the allocation equity of health resources in Guangxi Province. Mod Prev Med. 2016:43(22):4121-5.

9. Guangxi Bureau of Statistics. Guangxi statistical yearbook 2012. Beijing: China Statistics Press; 2012.

10. Guangxi Bureau of Statistics. Guangxi statistical yearbook 2013. Beijing: China Statistics Press; 2013.

11. Guangxi Bureau of Statistics. Guangxi statistical yearbook 2014. Beijing: China Statistics Press; 2014.

12. Guangxi Bureau of Statistics. Guangxi statistical yearbook 2015. Beijing: China Statistics Press; 2015.

13. Guangxi Bureau of Statistics. Guangxi statistical yearbook 2016. Beijing: China Statistics Press; 2016.

14. Zhang W, Chen D, Zhou H, et al. Regional health-care inequity in children's survival in Zhejiang Province, China. Int J Equity Health. 2016;15:188.
15. Liang S, Feng $Q$, Wang Y, et al. Studying on the equity of health resources allocation in the ethnic minority areas sampled with Guangxi. Chin Health Serv Manage. 2015;32(9):677-80.

16. Ma J, Xu J, Zhang Z. New cooperative medical scheme decreased financial burden but expanded the gap of income-related inequity: evidence from three provinces in rural China. Int J Equity Health. 2016;15:72.

17. Hong E. Income-related health inequalities across regions in Korea. Int J Equity Health. 2011;10:41.

18. Dorjdagva J, Batbaatar E, Dorjsuren B. Income-related inequalities in health care utilization in Mongolia, 2007/2008-2012. Int J Equity Health. 2015:14:57.

19. Chen M, Palmer AJ, Si L. Assessing equity in benefit distribution of government health subsidy in 2012 across East China: benefit incidence analysis. Int J Equity Health. 2016;15:15.

20. Yan K, Jiang Y, Qiu J, et al. The equity of China's emergency medical services from 2010-2014. Int J Equity Health. 2017;16:10.

21. Zhang $X$, Zhao L, Cui Z, et al. Study on equity and efficiency of health resources and services based on key indicators in China. PLoS ONE. 2015;10(12):e0144809.

22. Yuan S, Rehnberg C, Sun X, et al. Income related inequalities in new cooperative medical scheme: a five-year empirical study of Junan County in China. Int J Equity Health. 2014;13:38.

23. Zhou Z, Su Y, Gao J, et al. Assessing equity of healthcare utilization in rural China: results from nationally representative surveys from 1993 to 2008. Int J Equity Health. 2013;12:34

24. Zhou Z, Zhu L, Zhou Z, et al. The effects of China's urban basic medical insurance schemes on the equity of health service utilisation: evidence from Shaanxi Province. Int J Equity Health. 2014;13:23.

25. Zhang $T, X u Y$, Ren J, et al. Inequality in the distribution of health resources and health services in China hospitals versus primary care institutions. Int J Equity Health. 2017:16:42

26. Liu Y, Jiang Y, Tang S, et al. Analysis of the equity of emergency medical services: a cross-sectional survey in Chongqing city. Int J Equity Health. 2015;14:150.

27. Huang L, Yang D, Yao L, et al. Guangxi's rural health insurance scheme: evidence from an ethnic minority region in China. Rural Remote Health. 2013:13:2454.

28. Guo Z. Study on health resource configuration in 14 provincial cities of Guangxi during 2000-2010. Chongqing Med J. 2013;42(14):1618-20.

29. Xu K, Zhang K, Wang D. Trend in distribution of primary health care professionals in Jiangsu province of eastern China. Int J Equity Health. 2014;13:117.

30. Chen Y, Yin Z. Suggestions to ameliorate the inequity in urban/rural allocation of healthcare resources in China. Int J Equity Health. 2014;13:34.

31. Guo Z. The study on equity of configuration of medical resource in Guangxi. Med Philos. 2012;33(3):49-51.

32. Yang $L$, Sun J, Dong Q, et al. Health resources allocation in Guangxi and suggestions for solutions. Chin Rural Health Serv Adm. 2017;37(3):244-6.

\section{Submit your next manuscript to BioMed Central and we will help you at every step:}

- We accept pre-submission inquiries

- Our selector tool helps you to find the most relevant journal

- We provide round the clock customer support

- Convenient online submission

- Thorough peer review

- Inclusion in PubMed and all major indexing services

- Maximum visibility for your research

Submit your manuscript at www.biomedcentral com/submit
Ciomed Central 